\title{
HELM PINTAR BERBASIS ARDUINO PRO MINI UNTUK MENDETEKSI KECELAKAAN
}

\author{
Feri Agustina \\ Fakultas Ilmu Komputer, Program Studi Teknik Informatika \\ Universitas Dian Nuswantoro \\ Email: feri.agustina@dsn.dinus.ac.id \\ Zulfikar Adi Syahputra \\ Fakultas Ilmu Komputer, Program Studi Teknik Informatika \\ Universitas Dian Nuswantoro \\ Email: 111201609435@mhs.dinus.ac.id \\ De Rosal Ignatius Moses Setiadi \\ Fakultas Ilmu Komputer, Program Studi Teknik Informatika \\ Universitas Dian Nuswantoro \\ Email: $\underline{\text { moses@dsn.dinus.ac.id }}$
}

\begin{abstract}
ABSTRAK
Helm merupakan salah satu atribut yang wajib digunakan saat berkendara dengan sepeda motor. Helm berfungsi untuk melindungi kepala dari benturan saat terjadi kecelakaan. Insiden kecelakaan kendaaran bermotor banyak didominasi oleh kendaraan roda dua, dimana pada kasus tertentu dapat dimungkinan korban tidak membawa surat identitas maupun bisa melewati area yang sangat sepi, sehingga sulit dilakukan pertolongan pertama dan identifikasi korban. Penilitian ini bertujuan untuk membuat terobosan baru yaitu menciptakan helm pintar. Helm ini ditambahkan perangkat pintar yang disematkan pada spoiler helm, tujuannya untuk mengirimkan pesan beserta titik lokasi tempat kecelakaan. Perangkat pintar yang disematkan pada spoiler helm dibangun berbasis Arduino pro mini yang dipadukan dengan perangkat GPS, sensor kemiringan untuk mendeteksi kecelakaan, dan modul SIM 800L untuk mengirim notifikasi berupa SMS. Perangkat pintar juga dilengkapi dengan saklar untuk mematikan dan menghidupkan sistem. Berdasarkan hail pengujian Helm pintar sudah dapat bekerja dengan baik, dengan pemicu terjadinya kemiringan sebesar $180^{\circ}$ modul SIM $800 \mathrm{~L}$ dapat mengirimkan pesan berupa titik koordinat yang valid dan dapat dibuka langsung menggunakan google maps.
\end{abstract}

Kata kunci: helm pintar, arduino, deteksi kecelakaan, notifikasi SMS otomatis, berkendara dengan aman

\section{ABSTRACT}

A helmet is one of the attributes that must be used when riding on a motorcycle. A helmet serves to protect the head from collisions during an accident. The incidents of motorized vehicle accidents are mostly dominated by motorcycles, wherein certain cases it is possible for the victim not to carry an identity document or to be able to pass through very quiet areas, making first aid and victim identification difficult. This research aims to make a breakthrough, namely creating a smart helmet. This helmet is added with a smart device that is attached to the helmet spoiler, the goal is to send a message along with the location of the crash site. The smart device embedded in the helmet spoiler is built based on the Arduino pro mini combined with a GPS device, a tilt sensor to detect an accident, and an 800L SIM module for sending SMS notifications. Smart devices are also equipped with switches to turn off and on the system. Based on the results of the test, the Smart Helmet can work properly, with a trigger for a tilt of $180^{\circ}$ the $800 \mathrm{~L}$ SIM module can send messages in the form of valid coordinate points and can be opened directly using google maps.

Keywords: smart helmet, arduino, accident detection, automatic SMS notification, driving safely 


\section{PENDAHULUAN}

Keamanan dan keselamatan dalam berkendara merupakan hal penting dalam kehidupan seharihari khususnya saat melakukan perjalanan. Saat mengendarai kendaraan bermotor terdapat resiko kecelakaan yang dialami. Kecelakaan banyak terjadi akibat kelalaian pengendara. Berdasarkan statistik Korlantas Polri yang diberitakan pada laman otomotif.kompas.com terdapat 28.238 korban kecelakaan di Indonesia selama 31 Desember 2018 hingga 31 Maret 2019, dimana jumlah ini tergolong tinggi dan mengalami peningkatan dari sebelumnya. Sepeda motor merupakan jenis kendaraan yang sering terlibat kecelakaan [1]. Oleh sebab itu diperlukan peningkatan keamanan yang dapat menunjang keselamatan pengendara berupa pengamanan tambahan yang di butuhkan untuk menghindari akibat fatal terjadinya insiden saat berkendara, dalam peraturan UU No. 22 Tahun 2009, pasal 57 mengharuskan setiap warga negara yang berkendara menggunakan kendaraan bermotor harus menggunakan pengaman ketika berkendara dalam kegiatan yang melakukan mobilitas menggunakan kendaraan bermotor.

Beberapa cara yang sudah ditetapkan berupa aturan yang dikaji sesuai peraturan undang undang dasar negara Indonesia yang mengharuskan setiap pengendara bermotor khususnya sepeda motor harus menggunakan perlengkapan keamanan yang sudah terstandarisasi, alat pengamanan tersebut berupa helm, jaket, atribut surat identitas dan ijin untuk naik kendaraan dan lulus uji ijin mengemudi. Pada insiden kecelakaan kendaraan sepeda motor, dimungkinkan terjadi hal-hal yang tidak diinginkan misalnya sulitnya identifikasi korban terlebih apabila korban tidak membawa kartu identitas sehingga sulit menghubungi pihak keluarga.

Beberapa cara yang dianjurkan dari peraturan Undang - undang ada alat yang di gunakan untuk melindungi organ yang sangat fital yang terletak pada kepala yaitu helm yang di gunakan untuk melindungi kepala yang ditegaskan untuk mengurangi resiko dalam insiden kecelakaan yang berguna untuk membantu korban untuk mengurangi fenomena tidak sadarkan diri saat terjadi benturan yang keras pada kepala, namun cara tersebut masih menimbulkan fenomena yang lain seperti luka pada fisik yang menyulitkan pengendara bergerak dan tidak dapat melakukan meminta bantuan apalagi dalam perjalanan jauh dan lokasi yang minim mobilitas warga. Adapun cara yang kedua yaitu pada keluarga yang sedang pergi tidak kunjung dapat kabar dan tidak kunjung sampai maupun pulang, menimbukan kecemasan dan membuat keluarga melakukan pencarian manual dengan menanyai saudara, teman terdekat pengendara yang melakukan perjalanan dengan cara manual tersebut masih kurang efektif maka dilakukan juga laporan ke kepolisian yang harus dengan prosedur satu kali dua puluh empat jam yang mengakibatkan pengendara apabila terjadi kecelakaan maka akan telat mendapat pertolongan dan penanganan medis yang berdampak resiko terburuk yaitu tidak terselamatkan.

Perkembangan teknologi Global Positioning System (GPS) saat ini memungkinkan manusia mengakses objek dengan mudah. Dalam banyak hal penggunaan GPS telah banyak diterapkan seperti GPS tracker [2], implementasi GPS tracker misalnya pada penyewaan mobil untuk mengidentifikasi keberadaan mobil yang disewa. Penggunaan GPS juga dapat diterapkan dalam berbagai hal, dimana pada penelitian ini GPS tracker diimplementasikan pada helm yang mana disebut sebagai helm pintar. Helm ini ditambahkan fungsi keamanan untuk keselamatan pengendara berupa pendeteksi kecelakaan yang mampu mengidentifikasi kecelakaan, memberikan suara peringatan sebagai pertolongan pertama untuk pengendara apabila tidak sadarkan diri dan dapat melakukan tracking lokasi yang akan dikirimkan pesan SMS berupa notifikasi pada nomor HP keluarga. SMS notifikasi berisi informasi tracking lokasi yang dapat di akses menggunakan HP Android yang dapat langsung terintegrasi oleh layanan Google maps dapat digunakan untuk melihat lokasi akan di bangun menggunakan Mikrokontroler Arduino Pro mini dan sensor pendukung lainya.

Mikrokontroler Adruino telah banyak diterapkan untuk membuat aplikasi GPS tracking seperti pada penelitian [3], [4], selain itu juga banyak diterapkan dalam penelitian sistem tertanam seperti [5]-[7]. Arduino dipilih karena memiliki sumber yang terbuka sehingga banyak dikembangakan dan memiliki pustaka yang relatif lengkap, memiliki bootloader sehingga programmer tidak 
membutuhkan perangkat chip programmer, memiliki modul siap pakai, serta bahasa pemrograman yang populer yaitu bahasa $\mathrm{C}$.

\section{METODOLOGI PENELITIAN}

Pada penelitian ini helm pintar berbasis arduino dan modul GPS tracker dirancang. Mikrokontroler Arduino Pro Mini dirancang untuk diletakan pada spoiler helm. Pada Tabel 1 disajikan beberapa alat bahan yang digunakan untuk perancangan Helm pintar ini.

Tabel 1. Bahan yang digunakan untuk pembuatan Helm Pintar

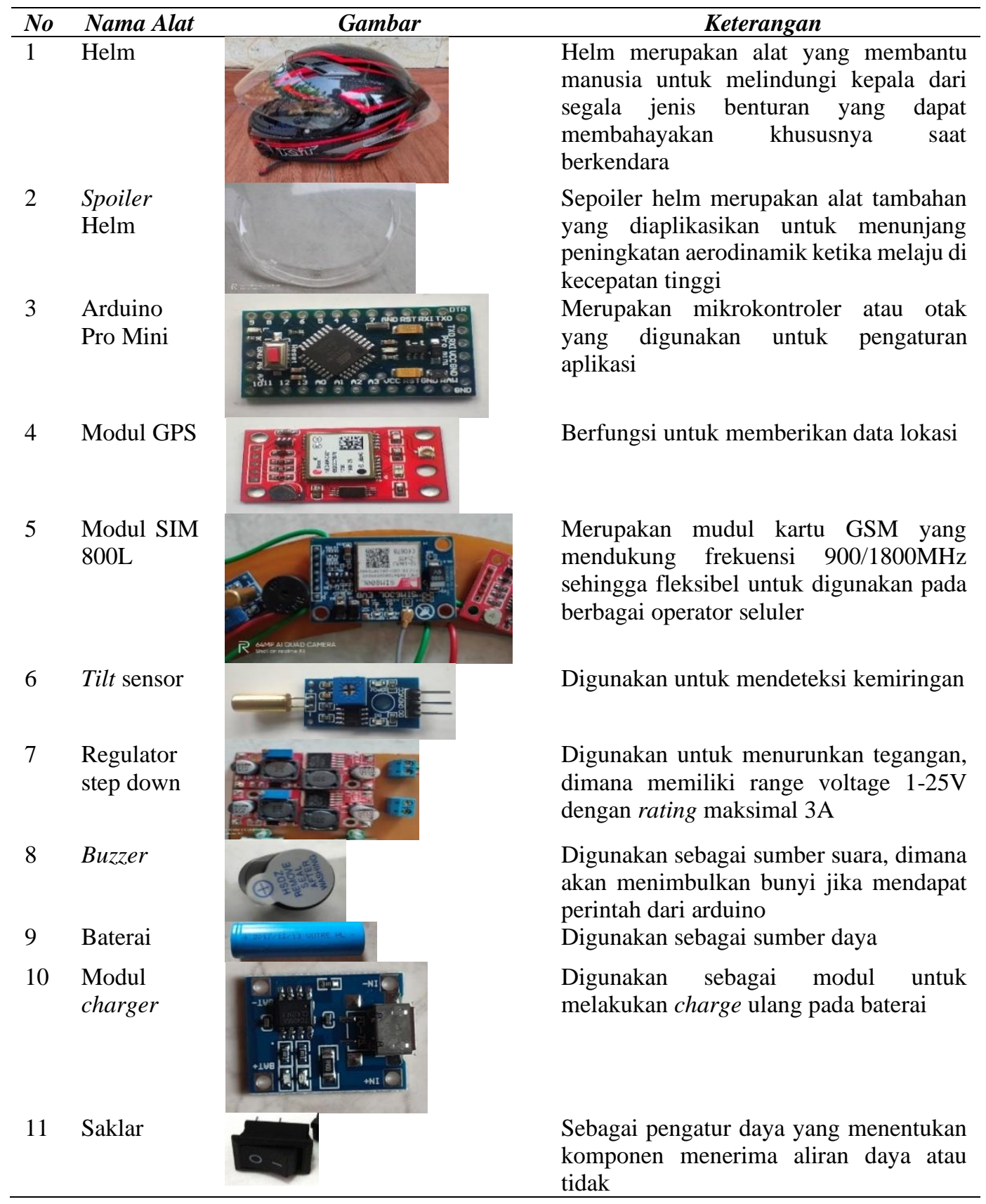


Selanjutnya dari alat dan bahan diatas dirancang spoiler helm pintar pendeteksi kecelakaan berbasis Mikrokontroler Arduino Pro Mini merupakan prototype alat yang memiliki fungsi kerja untuk membantu pengendara apabila mengalami insiden, alat ini akan bekerja apabila pengendara menyalakan tombol on pada alat untuk menyalakannya, kerja alat ini mendeteksi kemiringan dari helm yang akan diartikan bahwa pengendara mengalami insiden dan alat akan menyalakan buzzer sebagi sumber suara untuk meminta bantuan orang terdekat di lokasi insiden, kerja alat ini juga sebagai alat meminta bantuan otomatis yang akan mengirimkan pesan ke nomor yang ditetapkan dan memberikanya koordinat GPS yang akan langsung dapat diintegrasikan dengan layanan google maps dan langsung dibuka di aplikasinya untuk menunjukan lokasi. Untuk melihat perancangan secara lebih jelas dapat melihat Gambar 1.

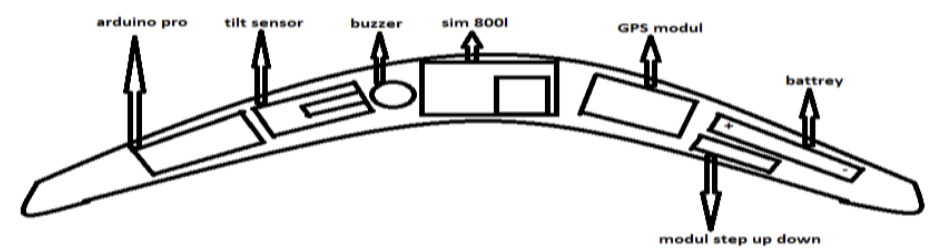

Gambar 1. Perancangan Spoiler yang Akan Ditempelkan Pada Helm

Setelah dilakukan persiapan alat dan bahan serta perancangan design spoiler helm. Program yang akan ditanamkan pada arduino akan dijelaskan pada Gambar 2.

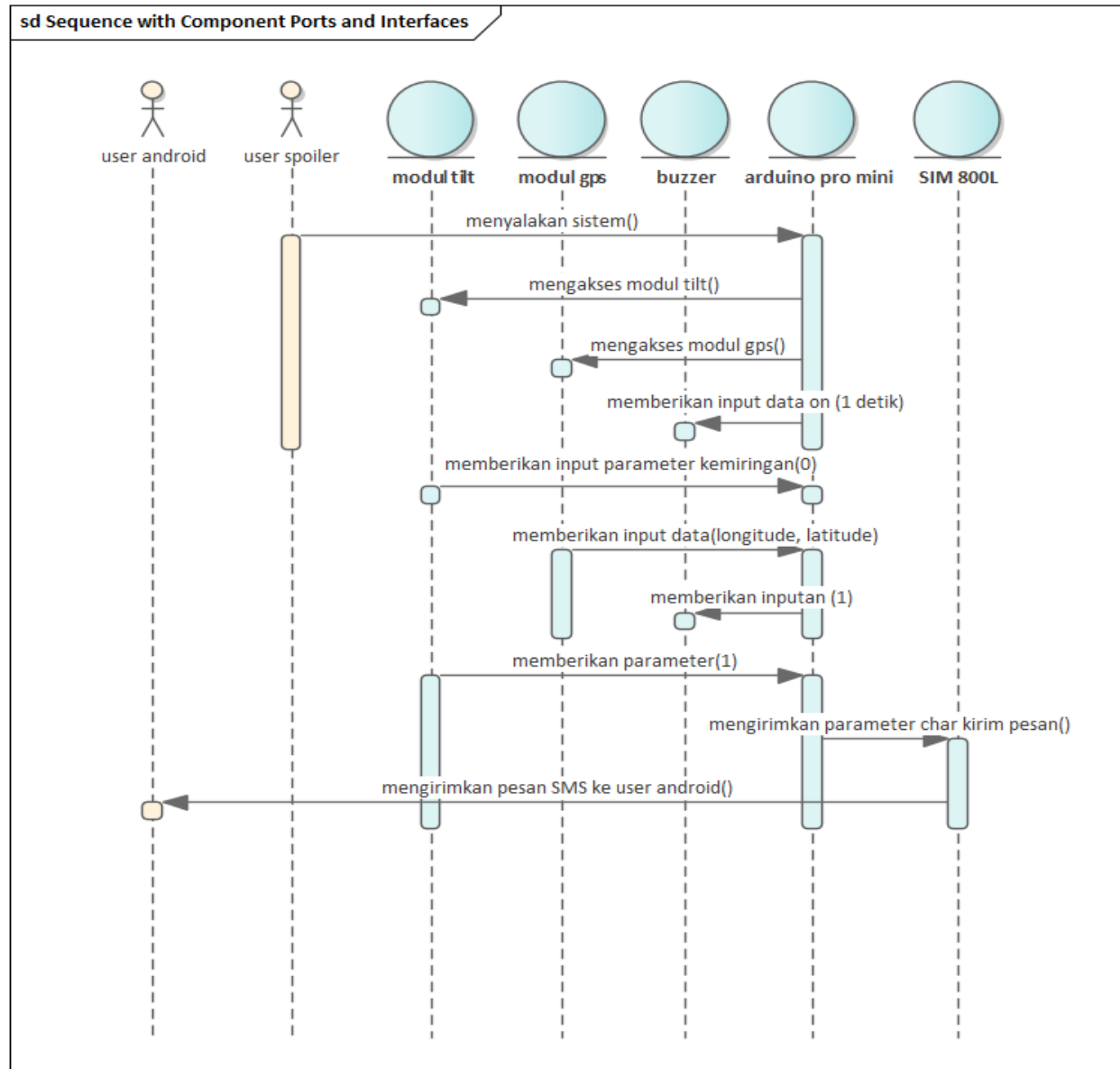

Gambar 2. Sequence Diagram Program 
Berdasarkan Gambar 2, ada dua aktor yang terlibat dalam sistem ini, yaitu user android dan user spoiler. User android bertugas dalam menerima pesan yang dikirimkan oleh sistem. Sedangkan user spoiler adalah pengendara sepeda motor yang menggunakan helm yang sudah dilengkapi dengan alat khusus berupa spoiler. Spoiler disini akan mengakses 4 (empat) modul yaitu modul tilt, modul GPS, modul arduino pro mini dan modul SIM 800L.

Spoiler akan menyalakan sistem dengan mengaktifkan modul arduino pro mini, dimana pada modul ini akan mengaktifkan modul tilt dan mengakses modul GPS sekaligus memberikan input data hidup pada modul buzzer.

Pada saat modul tilt yang berisi sensor kemiringan, mendeteksi tingkat kemiringan tertentu, ini artinya bahwa helm yang dikenakan oleh pengendara ada potensi kecelakan, maka modul tilt memberikan input kepada modul arduino pro mini agar mengaktifkan modul buzzer untuk aktif memberikan suara sekaligus mengaktifkan modul GPS untuk mengirimkan data lokasi berupa longitude dan latitude kepada user android sebagai pesan lokasi pengendara. Pesan akan dikirim oleh modul SIM 800L berupa sms lokasi kecelakaan tersebut kepada user android.

\section{HASIL DAN PEMBAHASAN}

Pada bagian ini dijelaskan implementasi perangkat lunak yang dibuat. Pada riset ini menggunakan Arduino IDE untuk menulis program, mengkompilasi, menggungah data ke mikrocontroler dan setting port input, outputnya. Ada tambahan library yang dipakai untuk mengalokasikan atau menambah port yang akan dipakai untuk melakukan komunikasi serial RX-TX. Library digunakan untuk menambahkan modul sensor agar modul tersebut dapat digunakan secara bergantian karena diatur menggunakan code library yang mempunyai sintaks mesin khusus untuk melakukan akses modul secara bergantian agar modul dapat berfungsi dan dapat mengirimkan parameter sesuai program yang diunggah dan akan menghasilkan parameter yang dapat dipakai untuk mendukung keputusan output, lebih lanjut dapat melihat Gambar 3.

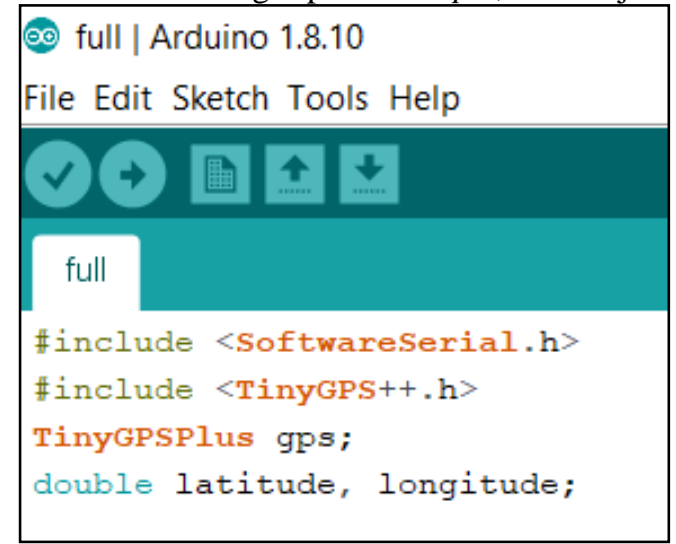

Gambar 3. Library yang Digunakan

Pada tahap berikutnya dilakukan inisialisasi port agar dapat mendukung komunikasi serial RX-TX. Selanjutnya juga dibuat fungsi setup untuk melakukan komunikasi dengan modul. Gambar 4 menunjukkan proses inisialisasi port dan fungsi setup.

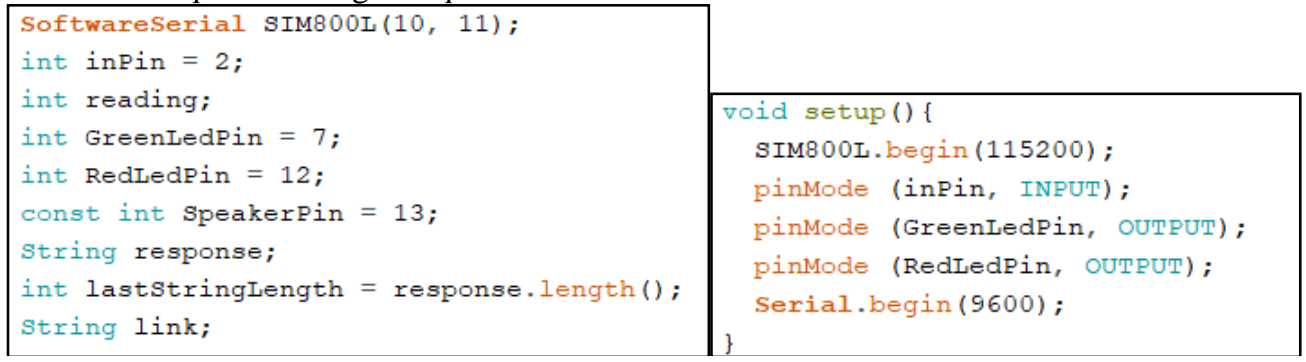


Pada tahap berikutnya dibuat fungsi loop yang digunakan untuk memberi keputusan hasil dari parameter yang di-setting. Fungsi loop dilakukan dalam perulangan terus-menerus tapi dengan menerapkan fungsi delay. Didalam fungsi loop terdapat perintah-perintah seperti penulisan pesan dan mengambil koordinat, yang selanjutnya menunjuk port input output untuk melakukan komunikasi serial RX - TX, secara lebih detail dapat melihat fugsi loop pada gambar 5.

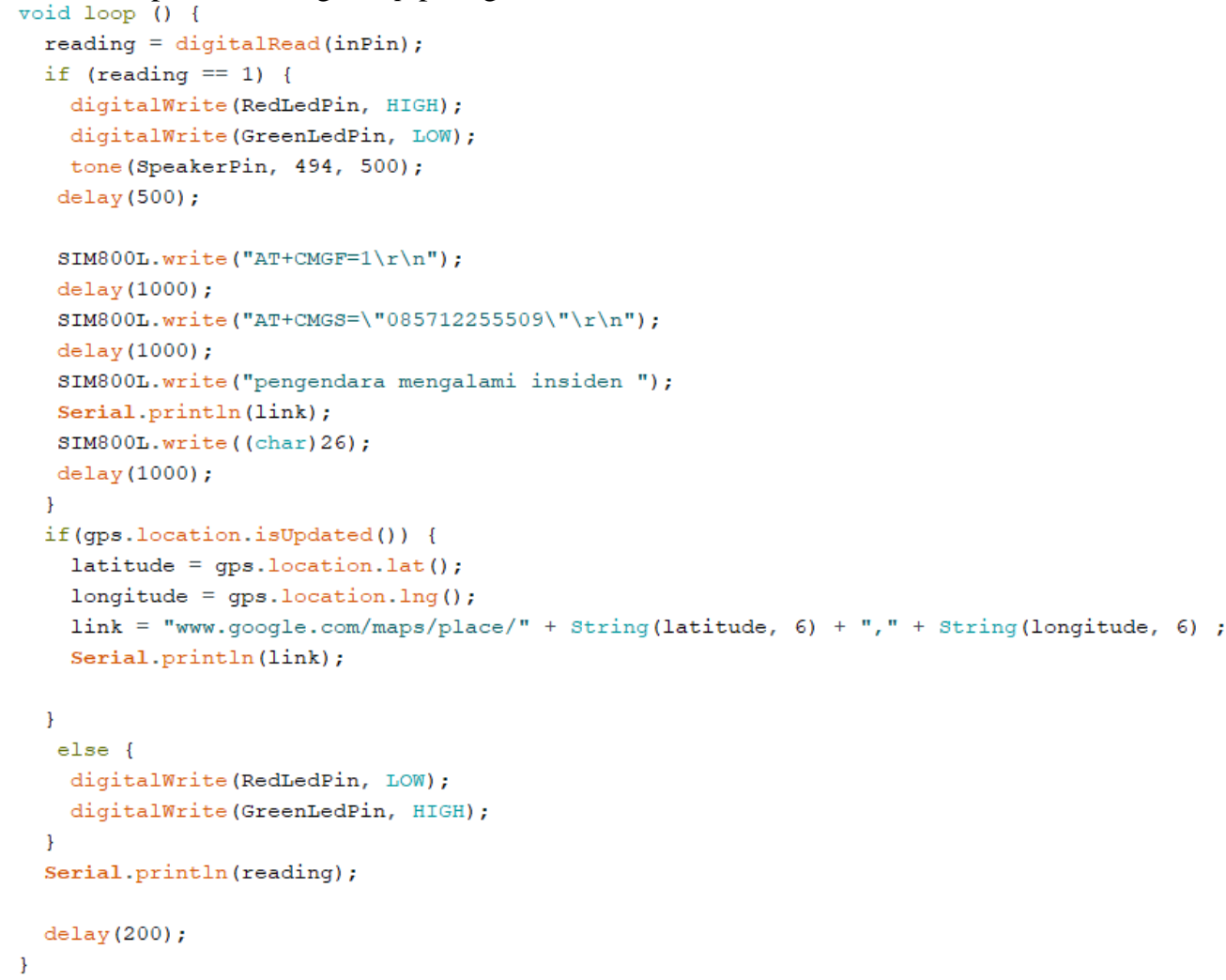

Gambar 5. Fungsi Loop

Perlu diketahui bahwa aplikasi ini hanya dihidupkan saat pengendara motor berkendara, inilah mengapa diperlukan saklar untuk mematikan dan menghidupkan sistem. Ketika pengendara mengalami insiden yang fatal mengakibatkan pengendara terjatuh maka helm dimungkinakan berada pada posisi miring, dalam kondisi seperti ini tilt sensor merupakan sensor yang akan di pakai untuk melakukan pengambilan parameter kemiringan yang mana tilt sensor dapat mendeteksi kemiringan sejauh 180 derajat. Oleh karena itu setelah dilakukan implementasi perangkat lunak, selanjutnya dilakukan implementasi perangkat perangkat keras. Implementasi perangkat keras dilakukan dengan perancangan rangkaian elektronik dan pembuatan jalur elektronik antar masing - masing modul agar dapat digabungkan menjadi sistem. Berikut urutan rancangan sistem masing - masing modul. Rangkaian pertama merupakan rangkaian GPS tracker yang menggunakan modul GPS dan modul arduino.

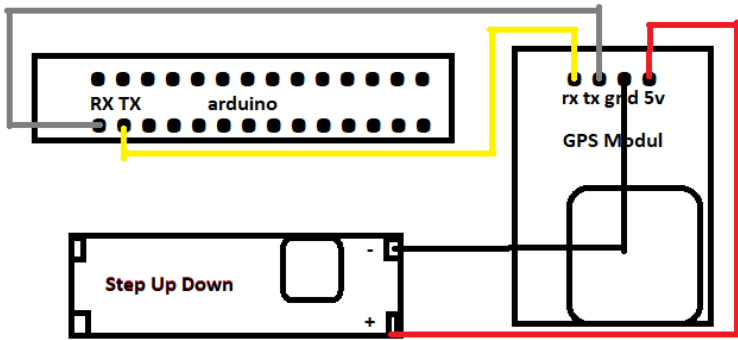

Gambar 6. Rangkaian GPS 
Dari Gambar 6, modul GPS memiliki 4 port yang berisi 5v, gnr, RX dan TX yang akan di gabungkan dengan arduino dan modul step up down. Modul GPS mengambil catu daya pada step up down sebesar 5v yang di simbolkan dengan jalur merah dan hitam. Jalur RX-TX di sambungkan ke arduino ke jalur RX TX untuk memberikan input data dilambangakan menggunakan jalur kuning dan hijau.

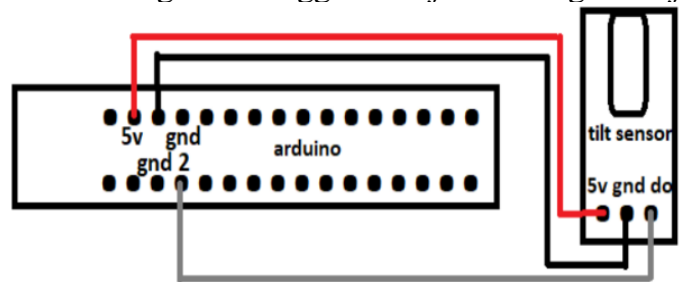

Gambar 7. Rangkaian Tilt Sensor

Rangkaian kedua merupakan rangkaian tilt sensor yang menggunakan tilt sensor dan arduino, yang disajikan pada Gambar 7. Dari gambar tersebut dapat dijelaskan bahwa tilt sensor mengambil tegangan langsung dari board arduino untuk menyalakan modul, tilt sensor menggunakan tegangan $5 \mathrm{v}$ yang di gambarkan dengan jalur merah dan hitam yang merupakan arus positif dan negatif. Port do merupakan port yang dideklarasikan diimplementasi software yang berguna untuk mengambil data kemiringan yang akan di input-kan sebagai kondisi apabila kemiringan lebih dari 45 derajat maka akan bernilai input 1 dan apabila kurang dari 45 derajat maka akan bernilai input 0 . Tilt sensor memiliki indikator pada modulnya berupa lampu yang akan mati apabila input-an kemiringan terpenuhi, akan hidup kembali apabila kemiringan normal.

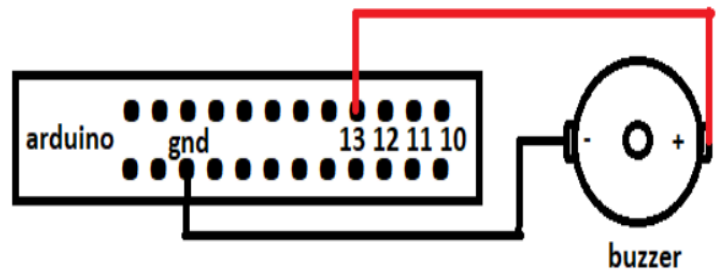

Gambar 8. Rangkaian Buzzer

Rangakaian ketiga merupakan rangkaian buzzer dan arduino pro mini rangkaian ini merupakan rangkaian yang akan mengeluarkan sumber bunyi apabila alat mengalami kemiringan, yang ditunjukan pada Gmabar 8. Modul buzzer menggunakan arus positif yang disambungkan dalam port 13 yang sudah di set pada saat inisialisasi dan arus negatif.

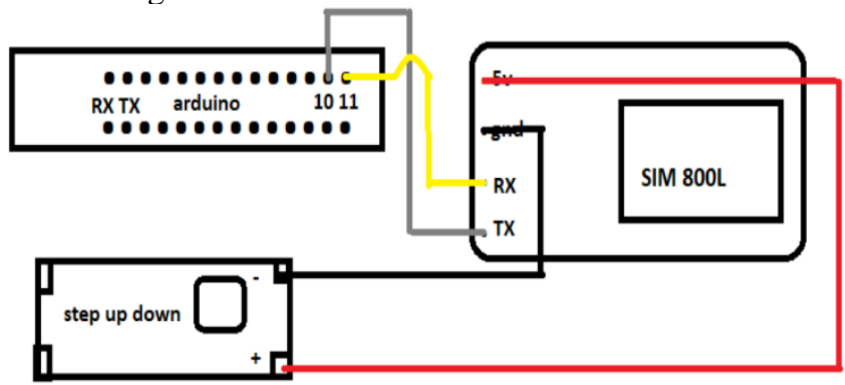

Gambar 9. Rangkaian SIM 800L

Rangkaian SIM 800L yang ditunjukan pada Gambar 9, merupakan rangkaian fungsi pengiriman pesan sebagai output-an data yang di hasilkan yang akan berinteraksi dengan smartphone dengan mengirimkan pesan berupa teks pengendara mengalami insiden dan mengirimkan kode koordinat yang dikirimkan oleh modul GPS. SIM 800L memerlukan daya sebesar 5v yang akan diambil dari step up down yang digambarkan menggunakan jalur warna merah sebagai positif dan jalur warna hitam sebagai negatif. Jalur RX-TX 
disambungkan ke port 11 dan port 10untuk melakukan komunikasi serial, yang disimbolkan dengan warna hijau dan kuning. Secara menyeluruh rangkaian diatas digambarkan pada Gambar 10. Sedangkan hasil pemasangan rangkaian pada helm disajikan pada Gambar 11.

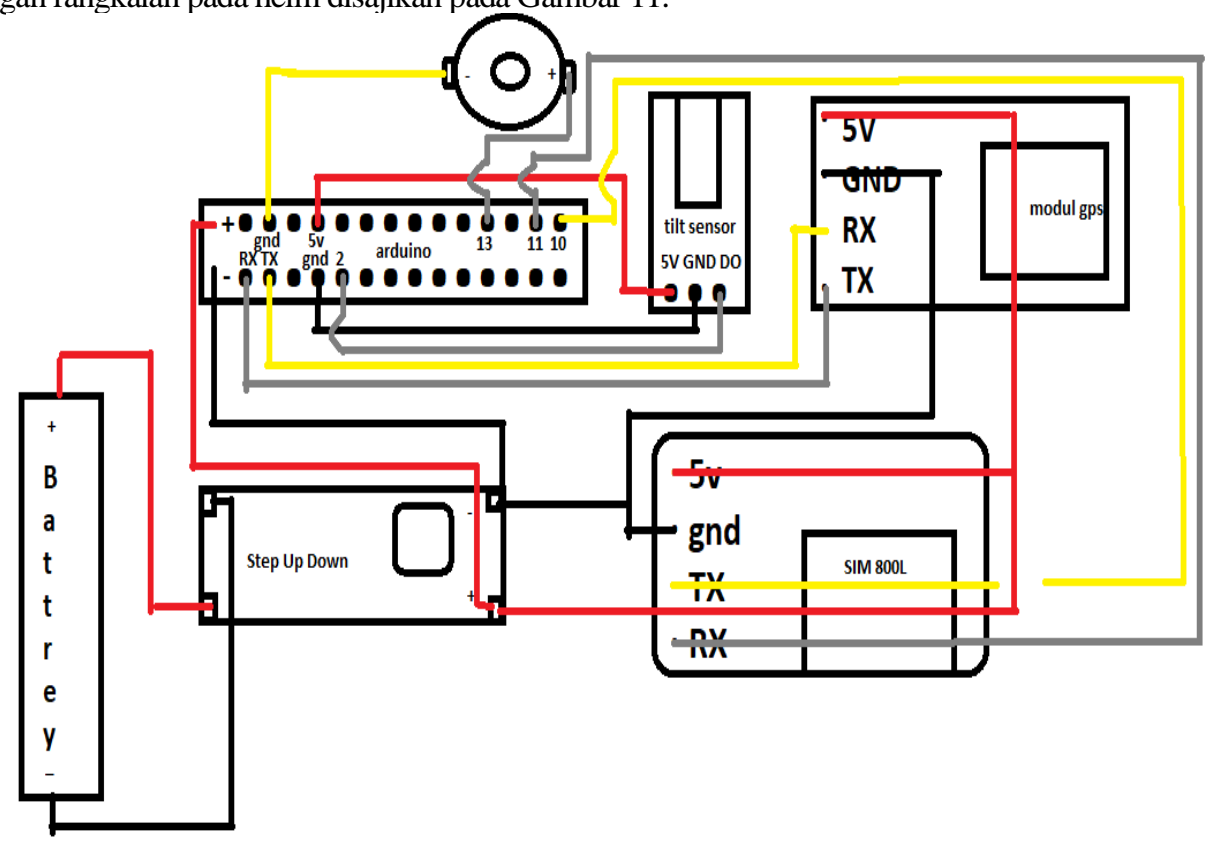

Gambar 10. Rangkaian Sistem Secara Menyeluruh

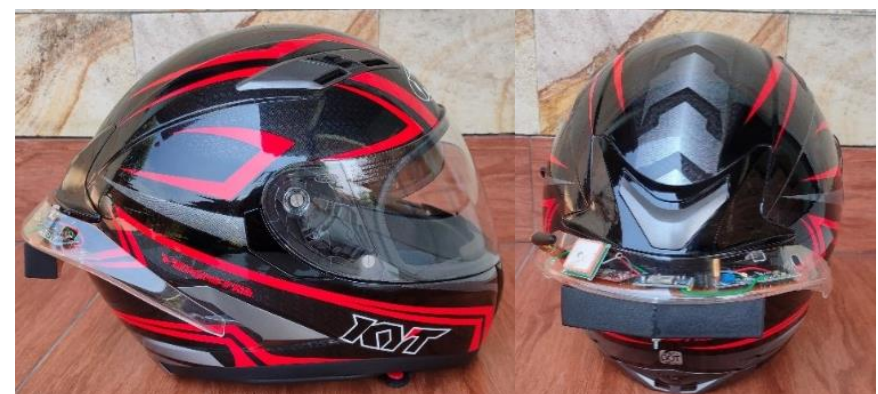

Gambar 11. Pemasangan Rangkaian Sistem pada Helm

Pada tahap berikutnya dilakukan pengujian sistem guna mengetahui tingkat keberhasilan perancangan alat yang telah dirancang serta direalisasikan. Pengujian yang menentukan hasil dari fungsionalitas sistem smart spoiler helm secara keseluruhan sesuai dalam Tabel 2. Selain itu pada Gambar 12, juga disajikan hasil pengujian terhadap koordinat GPS.

Tabel 2. Pengujian Sistem

\begin{tabular}{|c|c|c|c|c|}
\hline No & $\begin{array}{c}\text { Tahap } \\
\text { menjalankan alat }\end{array}$ & Hasil yang diharapkan & Hasil & Keterangan \\
\hline 1 & $\begin{array}{l}\text { Mendapatkan } \\
\text { koordinat data } \\
\text { longitude latitude } \\
\text { dari modul GPS }\end{array}$ & $\begin{array}{l}\text { Mendapatkan hasil sinyal } \\
\text { longitude latitude yang } \\
\text { akan dikompail langsung } \\
\text { dari data program arduino } \\
\text { yang akan dipakai sebagai }\end{array}$ & Sesuai & $\begin{array}{l}\text { Modul GPS mengeluarkan } \\
\text { indikator kedipan yang } \\
\text { sebelumnya ketika tidak } \\
\text { mendapat sinyal maka } \\
\text { indikator tidak berkedip, } \\
\text { setelah berkedip maka bisa di }\end{array}$ \\
\hline
\end{tabular}


2 Pengujian mendapatkan sinyal GSM dari modul SIM 800L

3 Pengujian pengiriman pesan bahaya dan pengiriman lokasi koordinat

4 Pengujian waktu tunggu GPS mendapat sinyal

5 Pengujian waktu tunggu SIM 800L Mendapat sinyal GSM

6 Pengujian kemampuan sensor mendapat parameter dari pengguna yang melakukan berkendara

7 Pengujian baterai yang digunakan mampu berapa lama dalam pemakaian

8 Pengujian koordinat yang di kirimkan alat lewat pesan teks pesan link target aplikasi dari google maps

Modul GSM mengeluarkan indikator yang menunjukan GSM mendapatkan sinyal seluler yang ditandai dengan berkedip lambatnya indikator lampu dalam modul yang berubah dari normal yang belum mendapat sinyal akan berkedip dengan cepat

Alat mampu mengirimkan pesan teks "pengendara mengalami insiden" dan koordinat google maps

Waktu tunggu GPS dari pertama on sampai indikator mendapatkan data dan siap untuk melakukan pengiriman sms berupa koordinat lokasi

Pengujian waktu on pertama dinyalakan sampai indikator menunjukan bahwa modul mendapat sinyal dan indikator mulai berkedip lambat

Sensor mampu mendeteksi dan mengirimkan indikator yang dipakai sebagai fungsi kirim SMS
Pengujian waktu yang di dapat untuk menyalakan dan mampu menahan arus dalam waktu tertentu

Mampu menunjukan titik koordinat lokasi dan dapat dibuka dengan aplikasi google maps artikan GPS mendapatkan sinyal.

sesuai Indikator pada modul sudah memberikan instrumen kedipan yang lambat sebagai indikasi SIM 800L mendapat sinyal GSM

sesuai

Alat mengirimkan pesan teks tersebut

Sesuai

Waktu tunggu yang di peroleh dari kemampuan GPS mendapat sinyal antara 1-5 menit tergantung kondisi dan situasi yang ada

Sesuai Waktu tunggu yang di ujikan untuk SIM 800L mencari sinyal GSM yang mempunyai waktu rata - rata 1-5 menit untuk mendapatkan sinyal GSM

Sesuai Ketika sensor yang di gunakan di pakai dalam berkendara kemiringan yang di-set cenderung lebih rentan terhadap guncangan namun sensor mampu mengidentifikasi guncangan dan kemiringan yang terjadi pada saat berkendara dan pada saat diam

Sesuai Baterai mampu hidup lebih dari 2 jam yang menunjukkan bahwa alat mampu dipakai untuk bertahan dalam waktu lebih dari 2 jam

sesuai Pesan dapat di-tap dan akan terintegrasi ke tautan aplikasi google maps dan menunjukan titik dari koordinat yang dikirim 


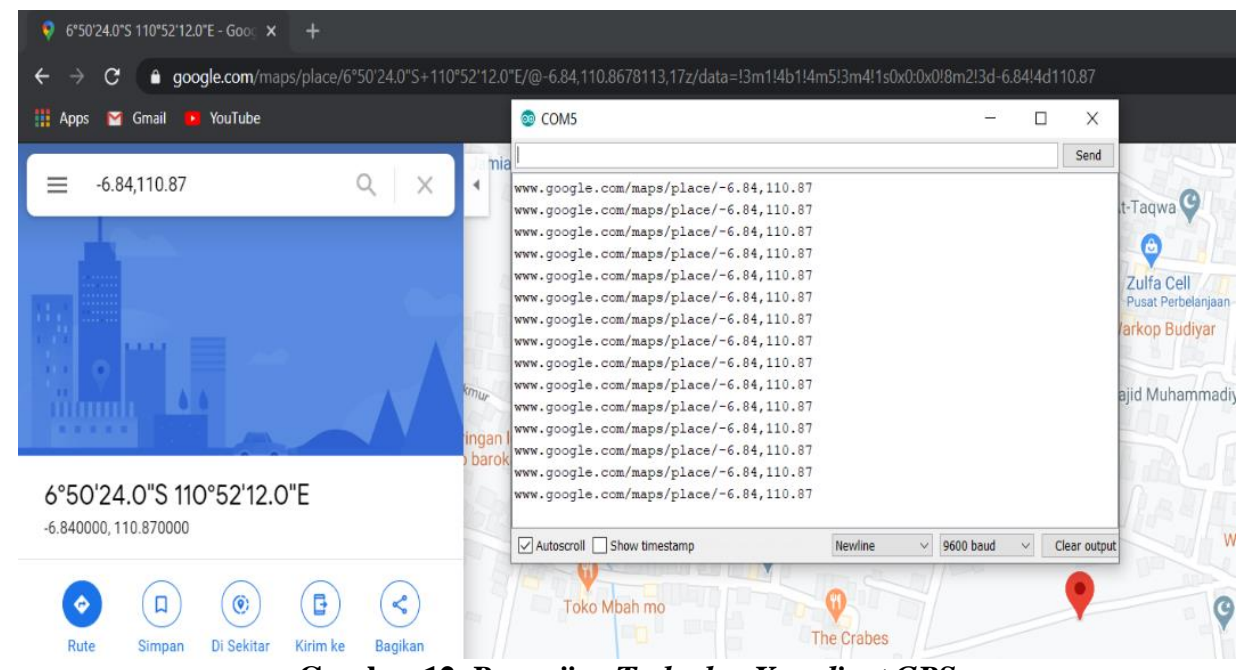

Gambar 12. Pengujian Terhadap Koordinat GPS

\section{KESIMPULAN}

Berdasarkan hasil dari penelitian yang telah dijalankan dapat disimpulkan bahwa Helm Pintar yang dibuat berhasil memiliki fitur dapat melakukan pemberian informasi secara cepat dan akurat pada saat terjadi insiden dan mengirimkan pesan ke nomor yang dituju berupa koordinat lokasi dan pemberitahuan untuk melakukan konfirmasi untuk memastikan apakah kondisi mengalami insiden apa tidak dan mempunyai fungsi sumber suara berupa buzzer yang dapat berbunyi apabila kondisi kemiringan terpenuhi dan berguna untuk mencari bantuan pada orang terdekat yang berada disekitar lokasi kejadian.

\section{DAFTAR PUSTAKA}

[1] D. Dananjaya, “Angka Kecelakaan Tahun 2019, Truk dan Sepeda Motor Sering Terlibat," Otomotif Kompas, 2019. [Online]. Available: https://otomotif.kompas.com/read/2019/09/09/160200815/angka-kecelakaan-tahun-2019truk-dan-sepeda-motor-sering-terlibat. [Accessed: 08-Oct-2020].

[2] A. Boukerche, B. Kantarci, and C. Kaptan, "Towards ensuring the reliability and dependability of vehicular crowd-sensing data in GPS-less location tracking," Pervasive and Mobile Computing, vol. 68. Elsevier B.V., p. 101248, 01-Oct-2020.

[3] S. Sumardi, "Sistem Keamanan Kendaraan Bermotor Menggunakan SMS dengan GPS Tracking Berbasis Arduino,” METIK J., vol. 3, no. 1, pp. 1-9, Jun. 2019.

[4] R. Rahardi and D. Triyanto, "Perancangan Sistem Keamanan Sepeda Motor sengan Sensor Fingerprint, SMS Gateway, dan GPS Tracker Berbasis Arduino dengan Interface Website," J. Coding, Sist. Komput. Untan, vol. 06, no. 03, pp. 118-127, Sep. 2018.

[5] A. S. Irtawaty and M. Ulfah, "Rancang Bangun Sistem Daur Ulang Minyak Goreng Bekas Berbasis Algoritma Fuzzy Logic,” Simetris J. Tek. Mesin, Elektro dan Ilmu Komput., vol. 9, no. 2, pp. 855-864, Nov. 2018.

[6] T. P. Satya, F. Puspasari, H. Prisyanti, and E. R. Meilani Saragih, "Perancangan dan Analisis Sistem Alat Ukur Arus Listrik Menggunakan Sensor Acs712 Berbasis Arduino Uno Dengan Standard Clampmeter," Simetris J. Tek. Mesin, Elektro dan Ilmu Komput., vol. 11, no. 1, pp. 
39-44, Apr. 2020.

[7] J. Nasir and C. Difo, "Penerapan Alat Tes Buta Warna Berbasis Arduino Uno," Simetris J. Tek. Mesin, Elektro dan Ilmu Komput., vol. 9, no. 2, pp. 925-934, Nov. 2018. 